\title{
Treatment trends and Medicare reimbursements for localized prostate cancer in elderly patients
}

Paolo Dell'Oglio ${ }^{* 1,2}$; Anne Sophie Valiquette ${ }^{* 1,3}$; Sami-Ramzi Leyh-Bannurah ${ }^{1,4}$; Zhe Tian $^{1,5}$; Vincent Trudeau ${ }^{1,3}$; Alessandro Larcher ${ }^{2}$; Shahrokh F. Shariat ${ }^{6}$; Umberto Capitanio ${ }^{2}$; Alberto Briganti ${ }^{2}$; Markus Graefen ${ }^{4}$; Francesco Montorsi ${ }^{2}$; Pierre I Karakiewicz ${ }^{1,3}$

${ }^{1}$ Cancer Prognostics and Health Outcomes Unit, University of Montreal Health Centre, Montreal, QC, Canada; ${ }^{2}$ Department of Urology and Division of Experimental Oncology, URI, Urological Research Institute, IRCCS San Raffaele Scientific Institute, Milan, Italy; ${ }^{3}$ Department of Urology, University of Montreal Health Centre, Montreal, QC, Canada; ${ }^{4}$ Martini-Clinic, Prostate Cancer Centre Hamburg-Eppendorf, Hamburg, Germany; ${ }^{5}$ Department of Epidemiology, Biostatistics, and Occupational Health, McGill University, Montreal, QC, Canada; ${ }^{6}$ Department of Urology, Medical University of Vienna and General Hospital, Vienna, Austria

${ }^{*}$ Co-first authors

Cite as: Can Urol Assoc J 2018 March 19; Epub ahead of print. http://dx.doi.org/10.5489/cuaj.4865

Published online March 19, 2018

$* * *$

Abstract

Introduction: The absolute and proportional numbers of elderly patients diagnosed with localized prostate cancer (PCa) are on the rise. We examined treatment trends and reimbursement figures in localized PCa patients aged $\geq 80$ years.

Methods: Between 2000 and 2008, we identified 30217 localized PCa patients aged $\geq 80$ years in Surveillance, Epidemiology and End Results (SEER)-Medicare-linked database. Alternative treatment modalities consisted of conservative management (CM), radiation therapy (RT), radical prostatectomy (RP), and primary androgen-deprivation therapy (PADT). For all four modalities, utilization and reimbursements were examined.

Results: PADT was the most frequently used treatment modality between 2000 and 2005. CM became the dominant treatment modality from 2006-2008. RP rates were marginal and RT ranked third and its annual rate increased from $20.77 \%$ in 2000 to $29.13 \%$ in 2008. Median individual reimbursement of RT was highest and ranged from \$29 343 in 2000 to \$31 090 in 2008, followed by RP (from $\$ 20560$ in 2000 to $\$ 19580$ in 2008), PADT (from $\$ 18901$ in 2000 to $\$ 8000$ in 2008) and CM (from $\$ 1824$ in 2000 to $\$ 1938$ in 2008). RT contributed to most of the cumulative annual reimbursements from 2003 (49.24\%) to 2008 (72.97\%). PADT ranked first from 2000 (54.56\%) to 2002 (50.49\%), but decreased by $19.40 \%$ in 2008. CM's contribution increased from $4.42 \%$ in 2000 to $6.96 \%$ in 2008 . RP share of reimbursements was stable during the study period.

Conclusions: Our results, focusing on localized PCa treatment in patients aged $\geq 80$ years, showed an important increase in rates, median cost, and proportion of cumulative cost related to RT. 


\section{Introduction}

Prostate cancer (PCa) is the most common non-cutaneous malignancy in American men, with estimates of 161,360 new cases for 2017. ${ }^{1}$ About one quarter (24.3\%) of patients are diagnosed after 75 years old. ${ }^{2}$ Elderly patients tend to have more aggressive or advanced tumors at diagnosis than their younger counterparts, but their shorter life-expectancy and increasing burden of comorbidities often limit their treatment options. ${ }^{3,4}$ Contemporary reports and guidelines favor conservative management (CM) for patients with localized PCa with a life-expectancy $\leq 10$ years. Moreover, no contemporary guidelines or reports recommend primary androgen deprivation therapy (PADT) in such individuals. ${ }^{5-10}$ Based on these considerations, we decided to assess the temporal trends of utilization of the four treatment modalities for localized PCa (CM, PADT, radical prostatectomy-RP, radiation therapy-RT) in elderly patients, as well as their associated cost. Reimbursement figures were used as a proxy of cost, as previously published. ${ }^{11-15} \mathrm{We}$ exclusively focused on clinically localized PCa patients aged $\geq 80$ years within the Surveillance, Epidemiology, and End Results (SEER)-Medicare database. We hypothesized an increased use of CM and decreased use of PADT, as well as low rates of active therapy such as RT and RP. A concordant decline in cost related to treatment of localized PCa in elderly patients was also expected.

\section{Methods}

\section{Data source and study population}

The current study relied on the SEER-Medicare insurance program-linked database. ${ }^{16}$ Between 2000 and 2008, we identified patients aged $\geq 80$ years, with clinically localized (stage T1-T2) histologically confirmed PCa (International Classification of Disease for Oncology [ICD-O] site code 61.9, histologic code 8140). Patients not enrolled in Medicare parts A or B and with health maintenance organization enrolment throughout the duration of the study were not considered. Patients were not included if PCa was diagnosed at autopsy or on death certificate only or if PCa was not the first malignancy recorded. Additional exclusions consisted of clinical stage T3 or T4 tumors, lymph node invasion and/or distant metastases and patients with unknown clinical stage.

We exclusively focused on patients who received primary treatment within six months after diagnosis. We classified treatment as either CM, RP, any form of RT or PADT. CM was defined as absence of active treatment within the first six months following diagnosis. We defined active treatment using Common Procedural Terminology, fourth edition (CPT-4), Healthcare Common Procedure Coding System (HCPCS) and International Classification of DiseaseNinth Revision (ICD-9) codes for RP, any form of RT and PADT (supplementary Table). RP group included patients who underwent surgery, with or without additional ADT or externalbeam RT. The RT group included patients with or without additional ADT. ADT included chemical (GnRH agonist or antiandrogen or both) or surgical castration. The final population resulted in 30,217 assessable patients aged $\geq 80$ years with localized PCa. 


\section{Covariates}

For each patient, age at diagnosis, year of diagnosis, race, marital status, United States (US) region (Midwest, Northeast, South and West according to the US Census Bureau) and population density were recorded. Socioeconomic status (SES) was defined according to three countyattribute variables (income, education, poverty levels), as previously described. ${ }^{16}$ The Charlson Comorbidity Index (CCI) was derived from Medicare claims recorded up to one year before PCa diagnosis, using a previously validated algorithm and categorized as 0 vs. 1 vs. $\geq 2 .{ }^{17}$ Tumor characteristics assessed included clinical stage (T1 or T2) and WHO grade (well-differentiated, moderately-differentiated, and poorly-differentiated disease).

\section{Medicare reimbursements}

We identified the amounts paid by Medicare for all individual inpatient, outpatient and physician services related to PCa diagnosis (code 185), for the first 12 months following diagnosis, during each calendar year of the study (2000-2008). The amounts related to individual reimbursements were tabulated according to each primary PCa treatment (CM vs. PADT vs. RT vs. RP) and were stratified by year of diagnosis. Thus generated amounts were used to tabulate annual reimbursement figures for each individual treatment modality. Subsequently, total annual reimbursement figures were calculated using the sum of all four examined treatment modalities. Finally, proportion contribution to the total annual reimbursements were calculated for each of the four examined treatment modalities. Costs were reported in 2016 US dollars, after adjustment

for annual US inflation rate. ${ }^{18}$ All reimbursement values were adjusted for age at diagnosis, year of diagnosis, race, marital status, US regions, population density, SES, clinical stage, WHO grade and CCI, using a log linear regression.

\section{Statistical analyses}

We first examined the temporal utilization trends for each of the four alternative treatment modalities, and graphically depicted it using the lowess smoother weighted function, with corresponding 95\% confidence intervals. The same methodology was used to assess the median annual reimbursement amount trends for each of the four treatment modalities (RT, PADT, RP and $\mathrm{CM}$ ), as well as the trends of each treatment's contribution to the proportion of the total annual Medicare reimbursement amounts. Central tendencies and dispersion measures were tabulated for each year of observation. Linear regression was used to test the slope of rates and cost of all examined treatment modalities over time. All statistical tests were performed using the RStudio graphical interface v.0.98 for R software environment v.3.0.2 (R Foundation, Vienna, Austria). All tests were two-sided with a significance level set at $p$-value $<0.05$.

\section{Results}

Overall, 30,217 patients aged $\geq 80$ years were identified between 2000 and 2008. Of those, 12,026 (39.8\%), 10,820 (35.8\%), 7,251 (24.0\%) and 120 (0.4\%) were treated with PADT, CM, RT and RP, respectively (Table 1). 
During the study period, the number of patients treated annually with one of the four examined treatment modalities ranged between 2,603 in 2008 to 3,755 in 2002 (Table 2). The two dominant treatment modalities throughout the study period (Figure 1) were CM and PADT. Specifically, PADT ranked first between 2000 (43.13\%) and 2005 (38.48\%; Table 2; Figure 1). Thereafter, its annual rate decreased to 29.53\% in 2008 ( $\mathrm{p}<0.001$; Table 2; Figure 1). CM ranked second between 2000 (35.75\%) and 2005 (36.08\%; Table 2; Figure 1). Thereafter, CM became the dominant treatment modality (from $36.50 \%$ in 2006 to $40.91 \%$ in 2008). The most important increase in CM use was observed between years 2003 (33.14\%) and 2008 (40.91\%; Table 2; $\mathrm{p}=0.02$; Figure 1). RT ranked third and its annual rate (Table 2) increased from $20.77 \%$ in 2000 to $29.13 \%$ in 2008 ( $<<0.001$; Figure 1). The most important increase in RT use was observed between year 2003 (21.82\%) and 2008 (29.13\%). RP ranked fourth and its annual use (Table 2) was marginal, with stable rates from $0.35 \%$ in 2000 to $0.43 \% 2008$ ( $\mathrm{p}=0.2$; Figure 1 ).

The median annual reimbursement trends, estimating costs for the treatment of an individual patient related to each of the four examined treatment modalities, are shown in Figures 2A-2D. The median reimbursements for RT ranged from \$29,343 in 2000 to $\$ 31,090$ in 2008 ( $\mathrm{p}=0.7$ ) vs. for PADT from $\$ 18,901$ in 2000 to $\$ 8,000$ in $2008(\mathrm{p}<0.001)$. The median reimbursements for RP ranged from \$20,560 in 2000 to \$19,580 in 2008 ( $p=0.9)$, with the lowest average reimbursement value of $\$ 13,412$ in 2004. RT ranked first within each of the nine examined study years. CM ranked last. Specifically, the median reimbursement for CM ranged from $\$ 1,824$ in 2000 to $\$ 1,938$ in 2008 ( $p=0.01$ ). On a proportion basis, in year 2000, relative to RT, PADT reimbursement amounts represented $64.4 \%$ vs. $70.1 \%$ for RP vs. $6.2 \%$ for CM. In year 2008, the same percentages were $25.7 \%$ for PADT vs. $63.0 \%$ for RP vs. $6.2 \%$ for CM.

The total reimbursement amount for all four treatment modalities examined was $\$ 52,498,205$ in 2000 vs. \$31,566,236 in 2008 (Table 2). The highest total reimbursement amount was recorded in $2002(\$ 67,372,730)$.

Proportionately (Table 2), PADT reimbursements ranked first (Figure 3) between year 2000 (54.56\%) and 2002 (50.49\%), and second thereafter (Table 2). RT reimbursements ranked second (Figure 3) from year 2000 (40.65\%) to 2002 (45.26\%), and first thereafter (Table 2). In 2008, RT accounted for the highest proportion of annual reimbursements recorded for the four examined treatment modalities (72.97\%). CM reimbursements ranked third (Figure 3) and contributed to $4.42 \%$ of the total amount in 2000 and to $6.96 \%$ in 2008 ( $p=0.009$; Table 2). RP share of cost remained stable during the study period $(0.37 \%$ in 2000 and $0.67 \%$ in 2008; $\mathrm{p}=0.08$; Table 2; Figure 3).

\section{Discussion}

In the current study we hypothesized an increase in the use of CM and a decrease in the use of PADT for localized PCa patients aged $\geq 80$ years. We also postulated that the rates of RT or RP would be low, given the advanced age of the study cohort. Moreover, a concordant decline in cost related to treatment of localized PCa in elderly patients was expected.

Our results confirmed some of our hypotheses. Specifically, the two main treatment modalities used in patients aged $\geq 80$ years were CM and PADT. Throughout the study years, we 
observed a decrease in PADT rates and an increase in CM rates. PADT was the dominant treatment modality until 2005. Thereafter, CM accounted for the highest treatment rates. Moreover, unexpectedly and despite the advanced age of the study cohort, RT rates also increased significantly between 2003 and 2008. RT represented the third most frequently used modality of the four examined treatments in patients aged $\geq 80$ years. Finally, RP rates remained marginally low during the study period.

Although RT was only the third most frequently used treatment modality, it accounted for the biggest share of cost between 2003 and 2008. The latter stems from its high median cost, which ranged from $\$ 29,343$ to $\$ 31,090$ and exceeded the median cost of all other examined treatment modalities. PADT share of cost decreased during the study period, from $54.56 \%$ in year 2000 to $19.40 \%$ in year 2008 , with respective medians of $\$ 18,901$ and $\$ 8,000$. These figures resulted in PADT being the second most important contributor to cumulative cost. CM's contribution to cumulative annual cost also increased from 4.42\% in 2000 to $6.96 \%$ in 2008, with its median cost ranging from $\$ 1,824$ in 2000 to $\$ 1,938$ in 2008. RP cost share remained stable and marginal, during the study period. It is also of note that the total annual reimbursements for all four treatment modalities for localized PCa in patients aged $\geq 80$ years decreased between years $2000(\$ 52,498,205)$ and $2008(\$ 31,566,236)$.

Of those observations, several require a comment. First, the proportion of cumulative cost related to RT sharply increased over the study period and nearly doubled. This happened out of proportion with the increase in RT rates. Indeed, the median cost of RT also increased over the study period and exceeded the median cost of all other treatment modalities throughout the study period. This finding is consistent with modifications in treatment patterns that occurred in the field of radiation oncology. Specifically, we witnessed an increased rate of costly variants of RT, such as intensity modulated and proton beam therapy. ${ }^{15,19}$ It is surprising though, that the uptake of such costly procedures occurred at such rapid rate in elderly patients, whose life expectancy might not be sufficient to warrant the use of any definitive therapy. Unfortunately, our database and its observational form do not allow to fully explore and justify the rationale of treatment selection. Despite the high cost of RT, the concordant decrease in PADT rates and the increase in $\mathrm{CM}$ rates jointly resulted in an overall decline in the total cost related to the treatment of localized PCa, in patients aged $\geq 80$ years. It is also of note that as of 2008 , the reimbursement figures for all treatment modalities declined due to a drop implemented by Medicare administrative. ${ }^{20}$

Other studies reported utilization rates of alternative treatment modalities for localized PCa in older patients. ${ }^{21-25}$ Of those, all focused on men aged $\geq 75$ years or younger. For example, a study by Hoffman et al. ${ }^{21}$ found treatment rates comparable to ours. Specifically, they observed that compared to their younger counterparts, men aged $\geq 75$ years were more likely to be treated with either PADT or CM, instead of RT or RP. However, other studies reported somewhat different findings. For example, Roberts et al. ${ }^{23}$ and Konety et al. ${ }^{25}$ reported utilization rates of alternative treatment modalities for localized PCa that ranged from 27 to 43\% for PADT, 34 to 52 \% for RT, 18 to $19 \%$ for CM and $4 \%$ for RP. It is of note that the proportions of RT use are higher and CM use are lower in those reports, than in the current study. These differences could be explained by difference in the definition of elderly age that was used. We exclusively relied on 
patients aged $\geq 80$ years, whereas others used age $\geq 75$ years. Younger patients are more likely to undergo active treatment such as RT, due to better health status and longer life-expectancy. It is well accepted that RT is more frequently used than RP in elderly patients, since no general anesthesia is required and fewer anesthesia related adverse events may be expected. ${ }^{24,26}$

Even though we advocate caution with respect to the use of definitive treatment modalities in the elderly, we wish to remind the reader of existing guidelines. The Society of Geriatric Oncology (SGO) has established guidelines for management of PCa in older men. ${ }^{27}$ According to these guidelines, clinicians should consider patient comorbidities, dependence status and nutritional status, along with tumor characteristics, more than chronological age to establish the health status and life-expectancy of elderly patients with localized PCa. According to these guidelines, healthy patients aged $\geq 80$ years, with life-expectancy of $\geq 10$ years should benefit from active therapy. This is based on similar cancer control outcomes in such selectively identified individuals, compared to their younger counterparts. ${ }^{28,29}$ On the other hand, patients with poor health status and low life-expectancy should undergo CM, as their probability of dying of cancer related causes is low. ${ }^{26,30}$ This said, no recommendation stipulates the use of PADT for localized PCa, in any patient including those aged $\geq 80$ years. Moreover, changes in Medicare reimbursement policies for PADT further discouraged the use of this modality. ${ }^{31}$

To the best of our knowledge, we are the first to examine the patterns of use of alternative treatment modalities for localized PCa and their cost in patients aged $\geq 80$ years. This assessment is important, as the aging of the population will contribute to increasingly higher proportion of elderly individuals diagnosed with localized PCa. This in turn, will require from clinicians a careful selection of treatment modalities for elderly patients and judicious use of health resources and health dollars.

Our study is not devoid of limitations. First, it relies on the SEER-Medicare database, as well as Medicare reimbursements, that are specific to the United States. Hence, the patterns observed in terms of use and cost according to the type of treatment may be different in the presence of other insurance providers and in analyses based on institutional charges. Moreover, differences in treatment assignment and cost figures could be observed in other countries than United States. In consequence, future studies are needed to confirm our findings. Moreover, our cost analyses relied on reimbursements related to PCa in the first year following diagnosis, using the ICD-9 PCa diagnostic code (185). This methodology may result in potential misclassification, due to omission or excessive use of this code. However, this potential limitation applies equally to all examined treatment modalities. Additionally, combination of RP and RT with other treatment modalities, such as ADT, may affect cost estimates. Last but not least, we examined trends between 2000 and 2008. However, cost and utilization rate figures may have changed in more contemporary years. For example, cost of most contemporary RT may have even further escalated. The reimbursement figures may or may have not followed that trend. Conversely, the most contemporary rates of RT use might have decreased in patients aged $\geq 80$ years. 


\section{Conclusions}

Our results, focusing on localized PCa treatment in patients aged $\geq 80$ years, showed that a surprisingly elevated proportion of elderly received RT. Moreover, an important increase in rates, median cost and proportion of cumulative cost related to RT was observed during the study period. 


\section{References}

1. Siegel RL, Miller KD, Jemal A. Cancer Statistics, 2017. CA: a cancer journal for clinicians. Jan 2017;67(1):7-30.

2. Howlader N, Noone AM, Krapcho M, et al. SEER Cancer Statistics Review, 1975-2012, National Cancer Institute

3. Bechis SK, Carroll PR, Cooperberg MR. Impact of age at diagnosis on prostate cancer treatment and survival. Journal of clinical oncology : official journal of the American Society of Clinical Oncology. Jan 10 2011;29(2):235-241.

4. Sun L, Caire AA, Robertson CN, et al. Men older than 70 years have higher risk prostate cancer and poorer survival in the early and late prostate specific antigen eras. The Journal of urology. Nov 2009;182(5):2242-2248.

5. Guidelines on prostate cancer. European Association of Urology. 2017; http://uroweb.org/guideline/prostate-cancer/.

6. National Comprehensive Cancer Network. Clinical Practice Guidelines in Oncology (NCCN Guidelines ${ }^{\circledR}$ ). Prostate cancer. 2017.

https://www.nccn.org/professionals/physician_gls/f_guidelines.asp

7. Thompson I, Thrasher JB, Aus G, et al. Guideline for the management of clinically localized prostate cancer: 2007 update. The Journal of urology. Jun 2007;177(6):21062131.

8. Sammon JD, Abdollah F, Reznor G, et al. Patterns of Declining Use and the Adverse Effect of Primary Androgen Deprivation on All-cause Mortality in Elderly Men with Prostate Cancer. European urology. Jul 2015;68(1):32-39.

9. Albertsen PC, Hanley JA, Fine J. 20-year outcomes following conservative management of clinically localized prostate cancer. Jama. May 4 2005;293(17):2095-2101.

10. Lu-Yao GL, Albertsen PC, Moore DF, et al. Fifteen-year survival outcomes following primary androgen-deprivation therapy for localized prostate cancer. JAMA internal medicine. Sep 2014;174(9):1460-1467.

11. Wang SY, Wang R, Yu JB, et al. Understanding regional variation in Medicare expenditures for initial episodes of prostate cancer care. Medical care. Aug 2014;52(8):680-687.

12. Warren JL, Yabroff KR, Meekins A, et al. Evaluation of trends in the cost of initial cancer treatment. Journal of the National Cancer Institute. Jun 18 2008;100(12):888-897.

13. Zeliadt SB, Etzioni R, Ramsey SD, et al. Trends in treatment costs for localized prostate cancer: the healthy screenee effect. Medical care. Feb 2007;45(2):154-159.

14. Snyder CF, Frick KD, Blackford AL, et al. How does initial treatment choice affect shortterm and long-term costs for clinically localized prostate cancer? Cancer. Dec 1 2010;116(23):5391-5399.

15. Nguyen PL, Gu X, Lipsitz SR, et al. Cost implications of the rapid adoption of newer technologies for treating prostate cancer. Journal of clinical oncology : official journal of the American Society of Clinical Oncology. Apr 20 2011;29(12):1517-1524. 
16. Warren JL, Klabunde CN, Schrag D, et al. Overview of the SEER-Medicare data: content, research applications, and generalizability to the United States elderly population. Med Care. Aug 2002;40(8 Suppl):IV-3-18.

17. Deyo RA, Cherkin DC, Ciol MA. Adapting a clinical comorbidity index for use with ICD-9-CM administrative databases. Journal of clinical epidemiology. Jun 1992;45(6):613-619.

18. US Inflation Calculator. Historical Inflation Rates: 1914-2017. http://www.usinflationcalculator.com/inflation/historical-inflation-rates/. Accessed 2016

19. Sheets NC, Goldin GH, Meyer AM, et al. Intensity-modulated radiation therapy, proton therapy, or conformal radiation therapy and morbidity and disease control in localized prostate cancer. Jama. Apr 18 2012;307(15):1611-1620.

20. Rosenthal MB. Nonpayment for performance? Medicare's new reimbursement rule. The New England journal of medicine. Oct 18 2007;357(16):1573-1575.

21. Hoffman RM, Shi Y, Freedland SJ, et al. Treatment patterns for older veterans with localized prostate cancer. Cancer Epidemiol. Jul 272015.

22. Konety BR, Sharp VJ, Raut H, et al. Screening and management of prostate cancer in elderly men: the Iowa Prostate Cancer Consensus. Urology. Mar 2008;71(3):511-514.

23. Roberts CB, Albertsen PC, Shao YH, et al. Patterns and correlates of prostate cancer treatment in older men. Am J Med. Mar 2011;124(3):235-243.

24. Bian SX, Hoffman KE. Management of prostate cancer in elderly men. Seminars in radiation oncology. Jul 2013;23(3):198-205.

25. Konety BR, Cowan JE, Carroll PR, et al. Patterns of primary and secondary therapy for prostate cancer in elderly men: analysis of data from CaPSURE. J Urol. May 2008;179(5):1797-1803; discussion 1803.

26. Abdollah F, Sun M, Thuret R, et al. A competing-risks analysis of survival after alternative treatment modalities for prostate cancer patients: 1988-2006. European urology. Jan 2011;59(1):88-95.

27. Droz JP, Aapro M, Balducci L, et al. Management of prostate cancer in older patients: updated recommendations of a working group of the International Society of Geriatric Oncology. The Lancet. Oncology. Aug 2014;15(9):e404-414.

28. Gandaglia G, Karakiewicz PI, Abdollah F, et al. The effect of age at diagnosis on prostate cancer mortality: a grade-for-grade and stage-for-stage analysis. Eur J Surg Oncol. Dec 2014;40(12):1706-1715.

29. Siddiqui SA, Sengupta S, Slezak JM, et al. Impact of patient age at treatment on outcome following radical retropubic prostatectomy for prostate cancer. The Journal of urology. Mar 2006;175(3 Pt 1):952-957.

30. Albertsen PC, Moore DF, Shih W, et al. Impact of comorbidity on survival among men with localized prostate cancer. Journal of clinical oncology : official journal of the American Society of Clinical Oncology. Apr 1 2011;29(10):1335-1341. 
31. Shahinian VB, Kuo YF, Gilbert SM. Reimbursement policy and androgen-deprivation therapy for prostate cancer. The New England journal of medicine. Nov 4 2010;363(19):1822-1832. 


\section{Figures and Tables}

Fig. 1. Temporal trends of treatments utilization for patients aged $\geq 80$ years with localized prostate cancer: conservative management (CM) vs. radical prostatectomy (RP) vs. radiation therapy (RT) vs. primary androgen-deprivation therapy (PADT), as recorded in 30217 patients between 2000 and 2008, within SEER-Medicare database (dotted lines: 95\% confidence interval).

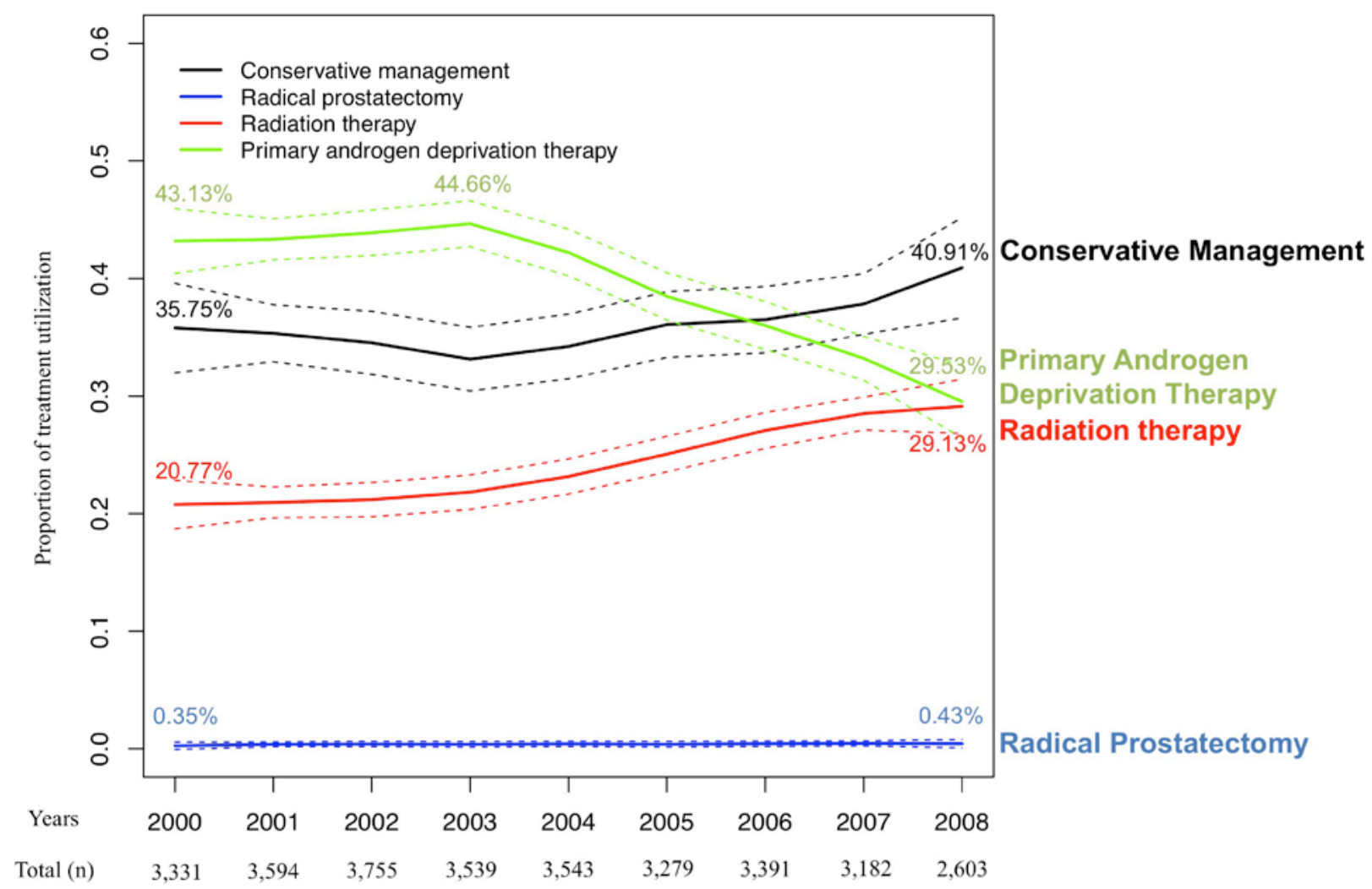


Fig. 2. Median annual reimbursement trends according to each treatment modality, for localized prostate patients aged $\geq 80$ years within SEER-Medicare database, between 2000 and 2008. (A) radiation therapy ( $\mathrm{n}=7251)$; $(\boldsymbol{B})$ primary androgen-deprivation therapy $(\mathrm{n}=12$ 026); $(\boldsymbol{C})$ radical prostatectomy $(n=120)$; and $(D)$ conservative management $(n=10,820)$. All reimbursement values were adjusted for patient and tumour characteristics.

Figure 2A: Radiation therapy

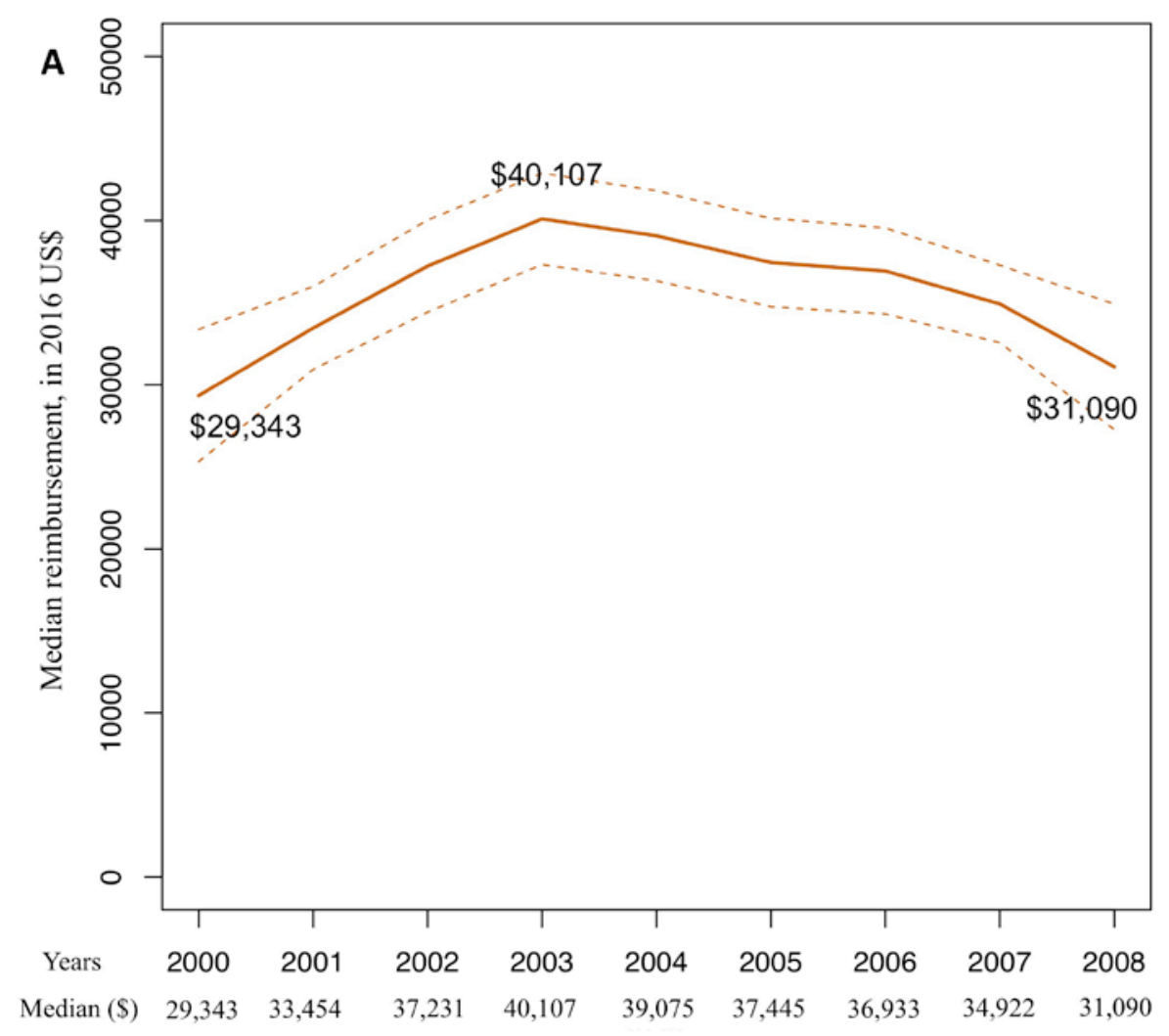


Figure 2B: Primary androgen deprivation therapy

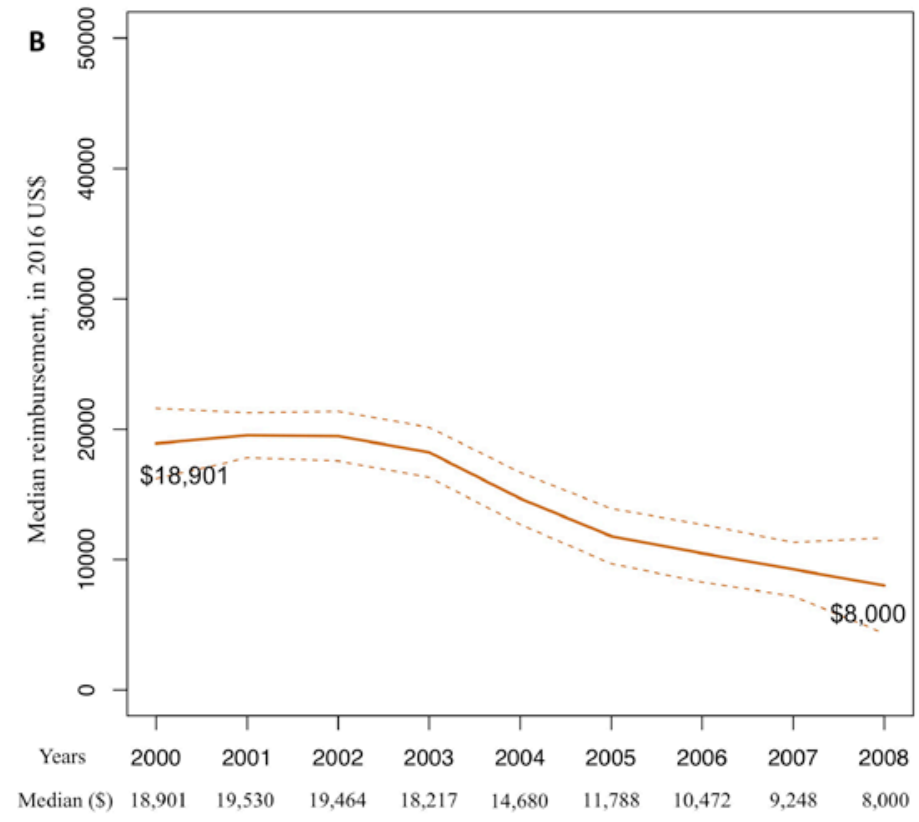

Figure 2C: Radical prostatectomy

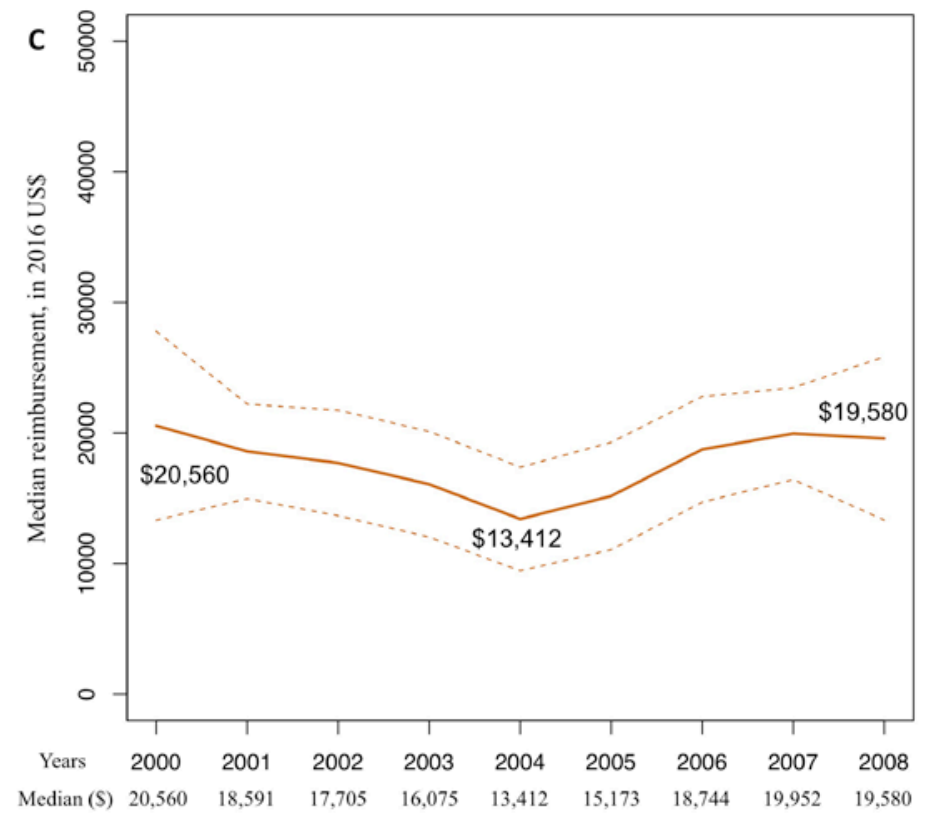


Figure 2D: Conservative management

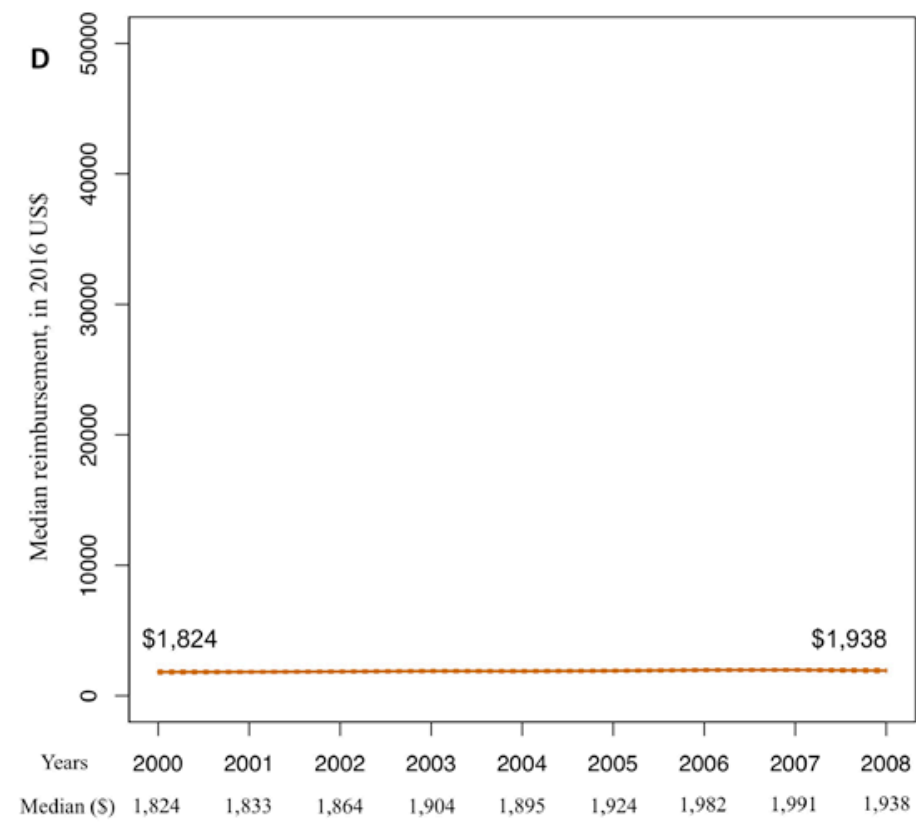


Fig. 3. Temporal trends depicting the proportion of the total annual reimbursement related to each of the four treatment modalities for localized prostate cancer: conservative management (CM) vs. radical prostatectomy (RP) vs. radiation therapy (RT) vs. primary androgen-deprivation therapy (PADT), as recorded in 30217 patients aged $\geq 80$ years between 2000 and 2008, within SEER-Medicare database. Annual cumulative reimbursement reflects a period of 12 months from diagnosis (dotted lines: 95\% confidence interval). All reimbursement values were adjusted for patient and tumor characteristics.

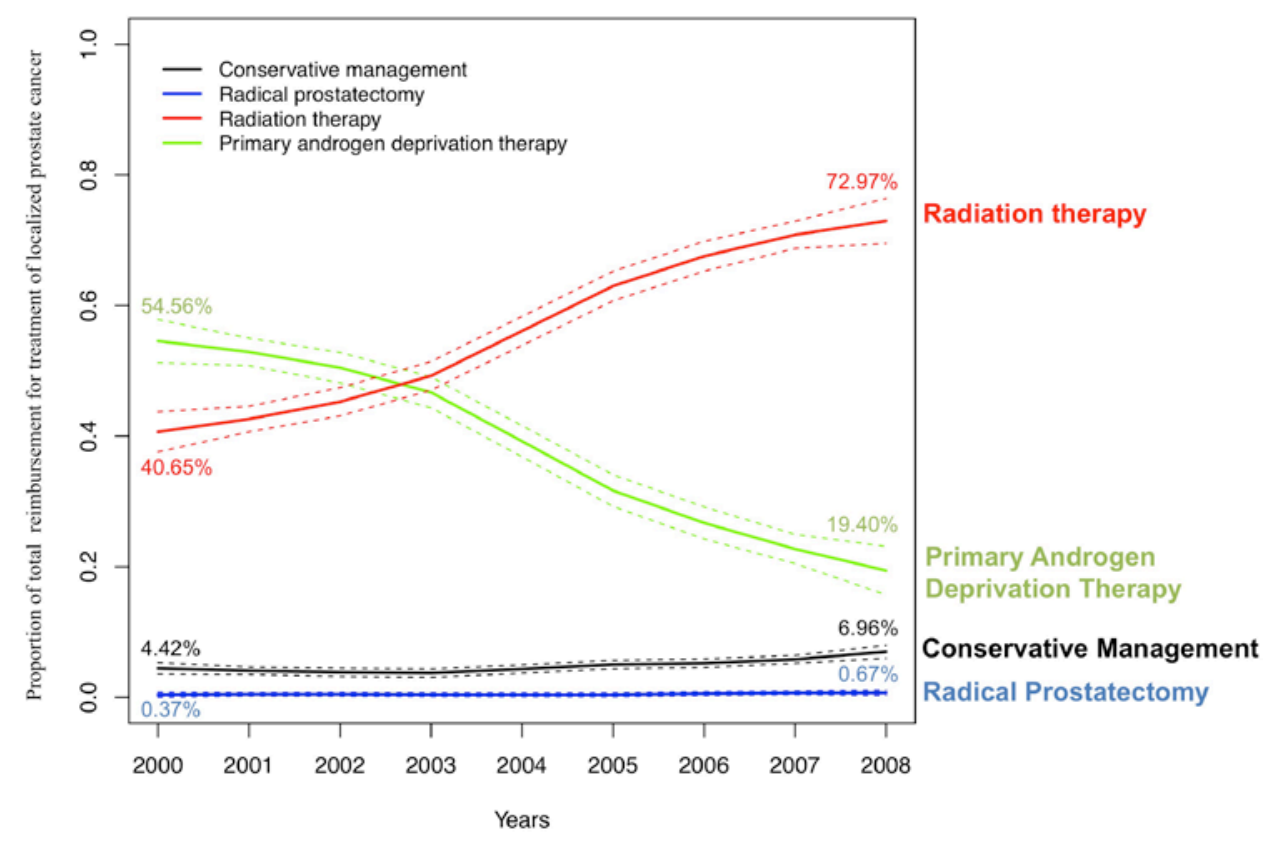




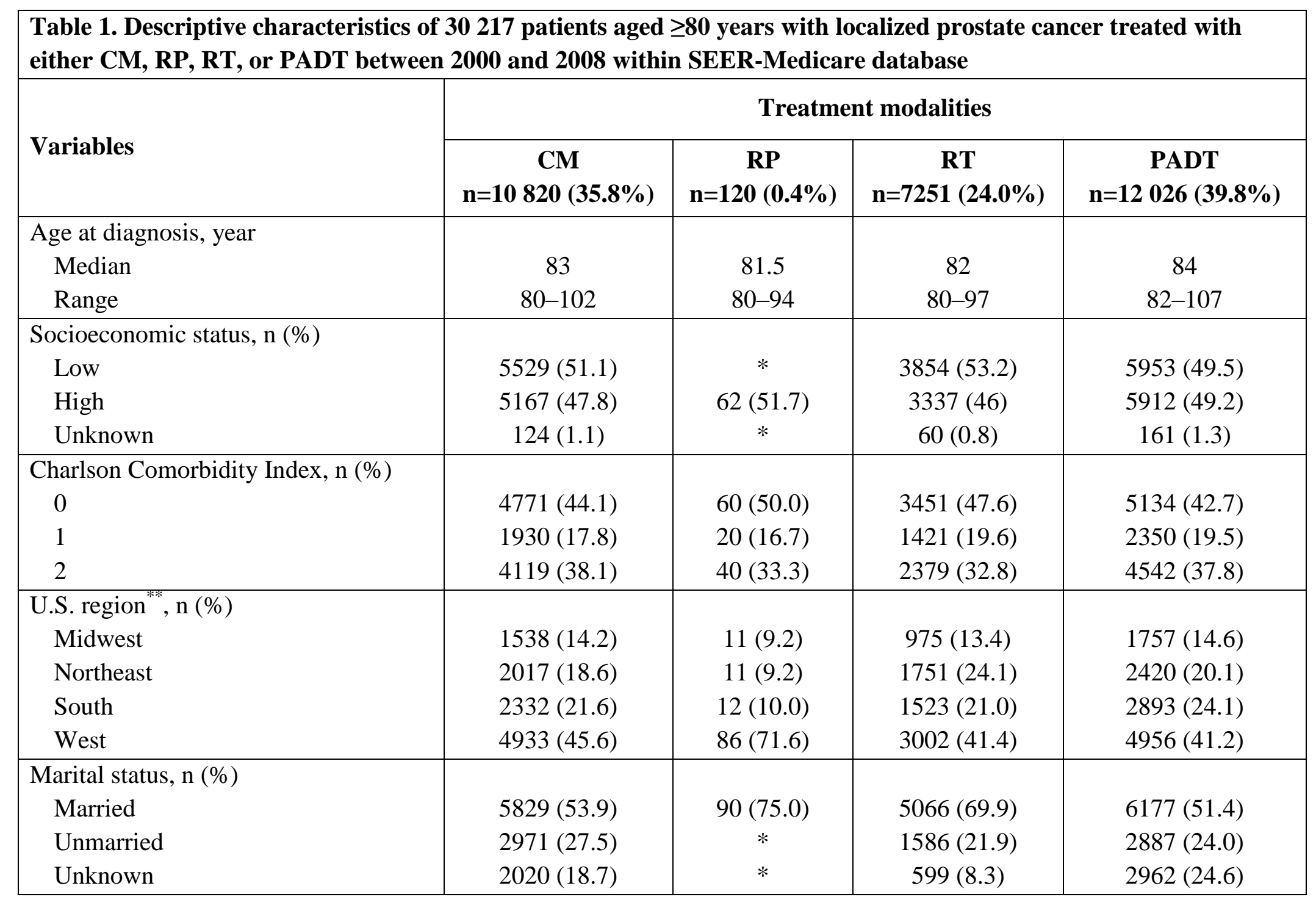




\begin{tabular}{|c|c|c|c|c|}
\hline $\begin{array}{l}\text { Population density, n (\%) } \\
\text { Urban } \\
\text { Rural }\end{array}$ & $\begin{array}{l}9082(83.9) \\
1738(16.1)\end{array}$ & * & $\begin{array}{c}6269(86.5) \\
982(13.5)\end{array}$ & $\begin{array}{l}9,741(81.0) \\
2,285(19.0)\end{array}$ \\
\hline $\begin{array}{l}\text { Grade, n (\%) } \\
\text { Well-differentiated } \\
\text { Moderately differentiated } \\
\text { Poorly differentiated } \\
\text { Undifferentiated/anaplastic } \\
\text { Unknown }\end{array}$ & $\begin{array}{c}557(5.1) \\
6348(58.7) \\
3382(31.2) \\
29(0.3) \\
504(4.7)\end{array}$ & $\begin{array}{c}* \\
* \\
69(57.5) \\
* \\
*\end{array}$ & $\begin{array}{c}78(1.1) \\
3164(43.6) \\
3889(53.6) \\
28(0.4) \\
92(1.3)\end{array}$ & $\begin{array}{c}182(1.5) \\
4805(40.0) \\
6676(55.5) \\
58(0.5) \\
305(2.5)\end{array}$ \\
\hline $\begin{array}{l}\text { Race, n (\%) } \\
\text { White } \\
\text { Black } \\
\text { Other } \\
\text { Unknown }\end{array}$ & $\begin{array}{c}9077(83.9) \\
1077(9.9) \\
647(6.0) \\
19(0.2)\end{array}$ & $\begin{array}{l}* \\
* \\
* \\
*\end{array}$ & $\begin{array}{c}6112(84.3) \\
495 \text { (6.8) } \\
* \\
*\end{array}$ & $\begin{array}{c}9947(82.7) \\
1155(9.6) \\
904(7.5) \\
20(0.2)\end{array}$ \\
\hline
\end{tabular}

*Masked for protection of patient confidentiality reasons, as per National Cancer Institute regulations. ${ }^{* *}$ Based on regions designated by the U.S. Census Bureau. CM: conservative management; PADT: primary androgen-deprivation therapy; RP: radical prostatectomy; RT: radiation therapy. 


\begin{tabular}{|c|c|c|c|c|c|c|c|c|c|}
\hline Year of study & 2000 & 2001 & 2002 & 2003 & 2004 & 2005 & 2006 & 2007 & 2008 \\
\hline $\begin{array}{l}\text { Number of patients } \\
\text { treated, } n\end{array}$ & 3331 & 3594 & 3755 & 3539 & 3543 & 3279 & 3391 & 3182 & 2603 \\
\hline \multicolumn{10}{|l|}{ Rate of treatment (\%) } \\
\hline $\mathrm{CM}$ & 35.75 & 35.33 & 34.53 & 33.14 & 34.23 & 36.08 & 36.50 & 37.83 & 40.91 \\
\hline $\mathrm{RP}$ & 0.35 & 0.38 & 0.40 & 0.38 & 0.41 & 0.38 & 0.42 & 0.46 & 0.43 \\
\hline $\mathrm{RT}$ & 20.77 & 20.95 & 21.19 & 21.82 & 23.15 & 25.06 & 27.08 & 28.51 & 29.13 \\
\hline PADT & 43.13 & 43.34 & 43.88 & 44.66 & 42.21 & 38.48 & 36.00 & 33.20 & 29.53 \\
\hline $\begin{array}{l}\text { Cumulative cost, US } \\
\$\end{array}$ & 52498205 & 56231917 & 67372730 & 63587682 & 57734801 & 46782316 & 50321689 & 46155006 & 31566236 \\
\hline \multicolumn{10}{|l|}{ Proportion of cost (\%) } \\
\hline $\mathrm{CM}$ & 4.42 & 4.05 & 3.81 & 3.69 & 4.31 & 5.00 & 5.21 & 5.80 & 6.96 \\
\hline $\mathrm{RP}$ & 0.37 & 0.44 & 0.44 & 0.38 & 0.37 & 0.36 & 0.54 & 0.66 & 0.67 \\
\hline $\mathrm{RT}$ & 40.65 & 42.62 & 45.26 & 49.24 & 56.12 & 62.99 & 67.55 & 70.84 & 72.97 \\
\hline PADT & 54.56 & 52.89 & 50.49 & 46.69 & 39.20 & 31.65 & 26.70 & 22.70 & 19.40 \\
\hline
\end{tabular}

CM: conservative management; PADT: primary androgen deprivation therapy; RP: radical prostatectomy; RT: radiation therapy. 


\begin{tabular}{|c|c|c|}
\hline \multicolumn{3}{|c|}{ Supplementary Table 1. Procedure codes for determining treatment type } \\
\hline Treatment & $\begin{array}{c}\text { ICD } 9 \text { procedure } \\
\text { codes }\end{array}$ & CPT codes/HCPCS \\
\hline Androgen-deprivation therapy & $\begin{array}{l}99.24,62.4,62.41, \\
62.42\end{array}$ & $\begin{array}{l}\text { 54520,54690,S0175,S9560,J1050,J1051,J1950,J3315,J9202,J9217, } \\
\text { J9218,J9219,J9165,C9216,C9430,G0356,J0128,S0165,J9225,J1056,J1380, } \\
\text { J1390,J0970,J1000,J1410 }\end{array}$ \\
\hline Radical prostatectomy & $60.5,17.42$ & $55866,55810,55812,55815,55840,55842,55845$ \\
\hline Any form of radiation therapy & $\begin{array}{l}92.23,92.24,92.25 \\
92.26,92.27\end{array}$ & $\begin{array}{l}\text { 77331,77332,77333,77334,77338,77399,77380,77381,77520,77522,77523, } \\
\text { 77525,4165F,77418,0073T,G0174,77402,77403,77404,77406,77407,77408, } \\
\text { 77409,77411,77412,77413,77414,77416,77422,77423,4200F,G0251,G033, } \\
\text { G0340,G0243,G0173 } \\
\text { 55859,55875,55876,55860,55862,55865,77750,77751,77752,77753,77754, } \\
\text { 77755,77756,77757,77758,77759,77760,77761,77762,77763,77764,77765, } \\
\text { 77766,77767,77768,77769,77770,77771,77772,77773,77774,77775,77776, } \\
\text { 77777,77778,77779,77780,77781,77782,77783,77784,77785,77786,77787, } \\
\text { 77788,77789,77790,77791,77792,77793,77794,77795,77796,77797,77798, } \\
\text { 77799,Q3001,A9527,C1164,C1174,C1325,C1350,C1700,C1701,C1703, } \\
\text { C1704,C1705,C1706,C1707,C1708,C1709,C1710,C1711,C1712,C1715, } \\
\text { C1716,C1717,C1718,C1719,C1720,C1728,C1790,C1791,C1792,C1793, } \\
\text { C1794,C1795,C1796,C1797,C1798,C1799,C1800,C1801,C1802,C1803, } \\
\text { C1804,C1805,C1806,C2616,C2638,C2639,C2640,C2641,C2632,C2633, } \\
\text { C2634,C2635,C2636,C2637,C2642,C2643,C2698,C2699,C9725,G0261, } \\
\text { G0256 }\end{array}$ \\
\hline
\end{tabular}

